\title{
A phase II study of catumaxomab administered intra- and postoperatively as part of a multimodal approach in primarily resectable gastric cancer
}

\author{
Carsten Bokemeyer • Alexander Stein · Karsten Ridwelski • Djordje Atanackovic • \\ Dirk Arnold • Ewald Wöll • Alexis Ulrich • Ramona Fischer • Colin Krüger • \\ Christoph Schuhmacher
}

Received: 19 May 2014/Accepted: 23 August 2014/Published online: 12 September 2014

(C) The International Gastric Cancer Association and The Japanese Gastric Cancer Association 2014

\begin{abstract}
Background Postoperative relapse rate after gastrectomy and perioperative chemotherapy remain high in patients with advanced gastric cancer due to the spread of disseminated tumour cells in the peritoneal cavity. Perioperative administration of catumaxomab could potentially eliminate residual tumour cells after intended curative resection of the primary tumour.

Methods This open-label, phase II study investigated the safety and efficacy of catumaxomab following neoadjuvant chemotherapy and subsequent surgery in patients with resectable (T2-4, N+, M0) gastric adenocarcinoma. Patients received catumaxomab intra- (single $10 \mu \mathrm{g}$ dose) and postoperatively $(10,20,50$ and $150 \mu \mathrm{g}$ on days 7,10 , 13 and 16, respectively). The primary endpoint was the postoperative complication rate (maximum rate defined as $<62 \%$ ) within 30 days after surgery in patients who received at least the first catumaxomab dose.
\end{abstract}

C. Bokemeyer, A. Stein have contributed equally.

C. Bokemeyer $(\bowtie) \cdot$ A. Stein · D. Atanackovic

Department of Internal Medicine II (Hematology, Oncology,

Bone Marrow Transplantation), University Medical Center

Hamburg-Eppendorf, Hamburg, Germany

e-mail: c.bokemeyer@uke.uni-hamburg.de

K. Ridwelski

Department of Surgery, Städtisches Klinikum Magdeburg,

Magdeburg, Germany

D. Arnold

Department of Medical Oncology, Tumour Biology Institute, Freiburg, Germany

E. Wöll

Department for Internal Medicine Zams, Saint Vincent Hospital

Zams, Zams, Austria
Results Of 64 patients treated with neoadjuvant chemotherapy, 58 underwent surgery and 54 received at least the first catumaxomab dose. Postoperative complications were reported in 18 of 54 evaluable patients (complication rate $33 \%$; $95 \%$ confidence interval: $21-48 \%$ ); thus, the primary endpoint was met. The most frequent complications were pulmonary infection $(17 \%)$ and anastomosis insufficiency requiring surgery $(11 \%)$. The most common catumaxomab-related adverse events were pyrexia (67\%), leucocytosis $(19 \%)$, abdominal pain $(17 \%)$ and chills $(17 \%)$. The 4-year disease-free and overall survival rates were 38 and $50 \%$.

Conclusion Intra- and postoperative administration of catumaxomab as part of a multimodal treatment approach was feasible and tolerable in patients with advanced gastric cancer and should be further investigated in a randomised trial.

Keywords Catumaxomab - Gastric cancer · Intraoperative $\cdot$ Multimodal treatment $\cdot$ Postoperative

A. Ulrich

Department of General, Visceral and Transplantation Surgery, University Hospital Heidelberg, Heidelberg, Germany

R. Fischer

Neovii (formerly Fresenius) Biotech GmbH, Munich, Germany

C. Krüger

Department of Surgery, Visceral, Thoracic and Vascular

Surgery, Vivantes Hospital of Neukoelln, Berlin, Germany

C. Schuhmacher

Department of Surgery, Klinikum rechts der Isar, Technische

Universität München, Munich, Germany 


$\begin{array}{ll}\text { Abbreviations } \\ \text { C } & \text { cisplatin } \\ \text { CI } & \text { confidence interval } \\ \text { CT } & \text { computed tomography } \\ \text { DFS } & \text { disease-free survival } \\ \text { E } & \text { epirubicin } \\ \text { EoT } & \text { end of treatment } \\ \text { EpCAM } & \text { epithelial cell-adhesion molecule } \\ \text { F } & \text { 5-fluorouracil } \\ \text { HR } & \text { hazard ratio } \\ \text { O } & \text { oxaliplatin } \\ \text { OS } & \text { overall survival } \\ \text { RECIST } & \text { Response Evaluation Criteria in Solid Tumours } \\ \text { TNM } & \text { tumour, lymph node and metastasis } \\ \text { UICC } & \text { Union for International Cancer Control } \\ \text { ULN } & \text { upper limit of normal } \\ \text { X } & \text { capecitabine }\end{array}$

\section{Introduction}

Globally, gastric cancer is the fourth most common form of cancer after lung, breast and colorectal, with an estimated 990,000 new cases in 2008, accounting for $8 \%$ of all new cancer cases [1]. In Europe, although the incidence of gastric cancer and its associated mortality are declining, it still accounts for approximately 107,000 deaths annually [2]. Localised gastric cancer is usually managed by a multimodal approach involving surgery, chemotherapy and/or radio (chemo) therapy, with surgical resection being the cornerstone of treatment [3, 4]. Molecular targeted agents are used in the palliative setting, e.g., trastuzumab for human epidermal growth factor receptor 2-positive metastatic disease or ramucirumab as salvage treatment, but are not yet established as part of perioperative therapy in resectable cases [5, 6].

Compared with surgery alone, the combination of perioperative chemotherapy with surgery has been shown to significantly improve survival in patients with locally advanced gastroesophageal and gastric cancer [7-9]. In patients without preoperative treatment, adjuvant chemotherapy or radiochemotherapy is associated with a statistically significant survival benefit in terms of overall survival (OS) and disease-free survival (DFS) compared to surgery alone $[10,11]$. However, the postoperative relapse rate after perioperative and adjuvant chemotherapy is still high, predominantly owing to the spread of disseminated micro-metastatic tumour cells in the peritoneal cavity, which occurs in approximately $20-30 \%$ of patients with advanced gastric cancer [12, 13]. Peritoneal carcinomatosis is the main site (about 40-50\%) of recurrence after curative resection of the primary tumour [14-16]. In addition, although perioperative chemotherapy improves survival, nearly half of patients are unable to tolerate or complete postoperative chemotherapy, usually due to prolonged recovery or postoperative complications $[8,9]$.

The targeted immunotherapy catumaxomab [Removab $^{\circledR}$, Neovii (formerly Fresenius) Biotech $\mathrm{GmbH}$, Munich, Germany] has been approved in the European Union since April 2009 for the intraperitoneal treatment of malignant ascites in patients with epithelial cell-adhesion molecule (EpCAM)-positive carcinomas for whom no further standard therapy is available or feasible [17, 18]. Catumaxomab, a trifunctional antibody, has two different antigen-binding sites for EpCAM on tumour cells and CD3 receptors on $\mathrm{T}$ cells, respectively, plus a functional $\mathrm{Fc}$ domain that binds to type I, IIa and III Fc $\gamma$ receptors on accessory cells, e.g., natural killer cells, macrophages and dendritic cells [19]. Catumaxomab exerts its antitumour activity via a complex immune reaction at the tumour site involving $\mathrm{T}$ cell-mediated lysis, antibody-dependent cellmediated cytotoxicity and phagocytosis, resulting in targeted elimination of tumour cells [20].

Catumaxomab has demonstrated efficacy and acceptable tolerability in the treatment of malignant ascites and has shown promising results in the treatment of advanced intraabdominal carcinoma, peritoneal carcinomatosis, gastric cancer and ovarian cancer [17, 21, 22].

In the pivotal study, 258 patients with various epithelial cancers, mainly ovarian $(50 \%)$ and gastric $(25 \%)$ cancer with chemotherapy refractory ascites, were randomised to paracentesis with or without catumaxomab. In the pooled patient population, a significant prolongation of puncturefree survival was shown [hazard ratio (HR) $0.254 ; 95 \%$ confidence interval (CI) $0.185-0.35 ; p<0.0001$ ] [17]. The beneficial trend in overall survival of the pooled population (HR 0.723, $95 \%$ CI 0.498-1.048; $p=0.085$ ) was markedly increased and significant in the gastric cancer subgroup (HR 0.469, $95 \%$ CI 0.232-0.951; $p=0.031$ ). Most relevant, grade $3 / 4$ adverse events were abdominal pain (9.6\% of patients), pyrexia (5.7\%), nausea (3.2\%), vomiting $(2.5 \%)$, anorexia $(3.2 \%)$, lymphopenia $(7.0 \%)$ and an increase in gamma-glutamyltransferase (5.7\%). Based on the proven efficacy and acceptable overall tolerability with rare grade 3/4 toxicities, further evaluation of catumaxomab in earlier treatment lines seemed reasonable.

Perioperative application of catumaxomab may provide the opportunity to eliminate disseminated tumour cells arising from gastric adenocarcinoma after intended curative resection of the primary tumour. This phase II study evaluated standard neoadjuvant chemotherapy given over three cycles followed by surgery together with intra- and postoperative application of intraperitoneal catumaxomab as a novel multimodal treatment concept for locally 
advanced gastric cancer. The primary objective was to determine the safety, tolerability and feasibility of this approach.

\section{Patients and methods}

\section{Study design}

This open-label, multicentre (Austria, Germany, Spain and the UK) phase II study investigated the safety and feasibility of catumaxomab after neoadjuvant chemotherapy in patients with a confirmed diagnosis of gastric adenocarcinoma and at risk for dissemination of tumour cells due to serosal infiltration or positive lymph nodes after subtotal or total gastrectomy with en bloc lymphadenectomy. Before surgery, patients received neoadjuvant chemotherapy consisting of three 21-day cycles. Two $( \pm 1)$ weeks after the last dose of chemotherapy, tumour re-staging [Union for International Cancer Control (UICC) tumour, lymph node and metastasis (TNM) stage] was performed and response to chemotherapy [Response Evaluation Criteria In Solid Tumours (RECIST), version 1.0] was assessed. At the investigator's discretion, 1-week therapy interruptions could be taken between chemotherapy cycles and dose reductions were permitted in the case of unacceptable toxicity. Surgery was performed within a time window of 4 $( \pm 2)$ weeks after completion of at least one cycle of neoadjuvant chemotherapy according to the D2 standard resection scheme [4].

The duration of surgery, number and region of lymph nodes dissected, histopathological status after resection, histological response to chemotherapy according to the Becker criteria and histological examination of all dissected lymph nodes ( $\geq 15$ lymph nodes) were recorded. If the intended surgical $\mathrm{R} 0$ resection could not be performed, a patient was nevertheless permitted to receive treatment with catumaxomab. Patients were excluded from catumaxomab therapy if distant haematogenic and lymphogenic metastases or peritoneal carcinomatosis were present (except for locally limited peritoneal carcinomatosis at the site of T3/T4 tumours), if thoracotomy and/or pancreas resection was required, or if tumour resection was not possible.

The study was designed, conducted and evaluated in compliance with the International Conference on Harmonisation guidelines on Good Clinical Practice, the Declaration of Helsinki and local regulatory requirements. All patients provided written informed consent before study admission. The study protocol, patient information sheet and informed consent form were approved by the independent ethics committee/institutional review board and competent authorities for each centre.
Endpoints

The primary endpoint was the rate of all predefined specific postoperative complications newly observed within 30 days after surgery in study patients who received at least the first dose of catumaxomab. Based on the results of the Medical Research Council Adjuvant Gastric Infusional Chemotherapy (MAGIC) trial [8], which reported an overall postoperative complication rate of $52 \%$ (46\% complications and $6 \%$ deaths) in patients with adenocarcinoma of the stomach, oesophagogastric junction or lower oesophagus, the maximum acceptable complication rate in this study was set at $62 \%$. Specific postoperative complications were defined as any death; any abscess requiring intervention (e.g., surgery or drainage); symptomatic cholecystitis verified by ultrasound or computed tomography (CT) scan; symptomatic pancreatitis verified by CT scan and at least one of the following objective diagnostic measurements: serum amylase $>3 \times$ the upper limit of normal (ULN) and serum lipase $>3 \times$ ULN; pulmonary infection verified by chest X-ray or CT scan; abdominal haemorrhage requiring any therapy; anastomosis insufficiency requiring surgery; ileus with grade IV clinical symptoms or requiring any surgical therapy; thromboembolism verified by at least one of the following objective diagnostic measurements: positive lung ventilation/perfusion scan (high probability according to Prospective Investigation of Pulmonary Embolism Diagnosis study criteria [23]), angiography or CT scan.

Adverse events (graded according to the National Cancer Institute Common Terminology Criteria for Adverse Events, version 3.0), laboratory results and vital functions were secondary safety endpoints. A further objective was to evaluate efficacy, determined by DFS and OS (calculated by Kaplan-Meier analysis from screening) within a 4-year follow-up period after the end of treatment (EoT) visit.

\section{Patients}

Patients aged $\geq 18$ years, with a primary diagnosis of a histologically confirmed gastric adenocarcinoma, including Siewert type 2 or 3 tumours of the gastroesophageal junction, TNM staging of T2/T3/T4, N \pm , M0 at screening, intended curative subtotal or total gastrectomy with en bloc R0-resection according to the standard D2 scheme, a Karnofsky Index score $\geq 70$ and a negative pregnancy blood test for women of childbearing potential were eligible for inclusion in this study. Exclusion criteria included exposure to prior cancer treatment (surgery, chemotherapy or radiotherapy) or planned adjuvant chemotherapy or radiotherapy before the EoT visit; prior diagnosis of any malignancy not cured by surgery alone $<5$ years before 
study entry, except for cervical carcinoma in situ and adequately treated non-melanoma skin cancer; previous use of non-humanised monoclonal mouse or rat antibodies; known or suspected hypersensitivity or allergy to catumaxomab or to similar antibodies or to any of the planned neoadjuvant chemotherapies; the presence of distant metastases; constant immunosuppressive therapy; bilateral pleural effusion; hypo-albuminaemia associated with hypovolaemia and hypotension; inadequate renal, hepatic or bone marrow function; symptomatic pyloric stenosis or any acute or chronic systemic infection or bowel obstruction within the previous 30 days.

\section{Staging}

Tumour staging, using routine diagnostic measures as clinically indicated (e.g., X-rays, computed tomography, magnetic resonance imaging, sonography, endoscopy. etc.), was performed at screening to determine the initial clinical TNM status and after chemotherapy at the postchemotherapy control visit to determine the preoperative TNM status. Tumour staging was performed after surgery for the pathological TNM (pTNM) status, taking into account the final histopathological results.

\section{Treatment}

Prior to surgery and the start of catumaxomab treatment, all patients received neoadjuvant chemotherapy consisting of (1) epirubicin (E) $50 \mathrm{mg} / \mathrm{m}^{2}$ intravenous bolus on day 1 , plus cisplatin (C) $60 \mathrm{mg} / \mathrm{m}^{2}$ 4-h intravenous infusion on day 1 and capecitabine (X) $625 \mathrm{mg} / \mathrm{m}^{2}$ oral twice daily (ECX) on days 1-21; (2) E plus oxaliplatin (O) $130 \mathrm{mg} / \mathrm{m}^{2}$ 2-h intravenous infusion on day 1 and X (EOX); (3) E plus $\mathrm{C}$ and 5-fluorouracil (F) $200 \mathrm{mg} / \mathrm{m}^{2} /$ day continuous intravenous infusion over 21 days via an intravenous port system or $2,000 \mathrm{mg} / \mathrm{m}^{2} /$ day 24 -h infusion once weekly, with folic acid $500 \mathrm{mg} / \mathrm{m}^{2}$ administered $2 \mathrm{~h}$ before each infusion (ECF); or (4) E plus $\mathrm{O}$ and $\mathrm{F}$ (EOF), depending on the choice of the investigator. Catumaxomab treatment consisted of an initial $10 \mu \mathrm{g}$ dose administered intraperitoneally directly into the abdomen at the end of the surgery after resection but before wound closure. The subsequent postoperative doses $(10,20,50$ and $150 \mu \mathrm{g})$ were administered as 3-h intraperitoneal infusions using an abdominal intraperitoneal port on days 7, 10, 13 and 16, respectively, after surgery. Thirty minutes before each infusion, patients received paracetamol $1,000 \mathrm{mg}$ as premedication (intravenously over $15 \mathrm{~min}$ intraoperatively and orally postoperatively). Other nonsteroidal, antiinflammatory drugs (e.g., ibuprofen) could be given as an alternative at the discretion of the investigator. To enable optimal distribution of catumaxomab, $500 \mathrm{ml}$ of $0.9 \%$ sodium chloride solution was administered intraperitoneally before each postoperative catumaxomab infusion. The minimal time interval between two catumaxomab infusions was $72 \mathrm{~h}$, and the total treatment period was not to exceed 21 days. The EoT visit occurred 1 month ( \pm 1 week) after the last catumaxomab infusion or after surgery if the patient was excluded from catumaxomab therapy. During the followup period, patients were assessed (via telephone calls or personal visits) at $3,6,9,12,18,24,36$ and 48 months ( \pm 2 weeks) after the EoT.

\section{Statistics}

The study design was customised to the specific binary endpoint of postoperative complications with an opposite scale, i.e., low rates are favourable. The study hypothesis was defined as $\mathrm{H}_{0}: \mathrm{c}_{0} \geq 62 \%$ versus $\mathrm{H}_{1}: \mathrm{c}_{1} \leq 42 \%$, where $\mathrm{c}$ is the postoperative complication rate. The minimum complication rate for a poor outcome was $62 \%$, while the maximum complication rate for a good outcome was $42 \%$. If the complication rate was $\geq 62 \%$, the regimen would be considered unsuitable and if $\leq 42 \%$ would be considered suitable for further investigation. If the complication rate was $\leq 51 \%$, the hypothesis that the complication rate is $\geq 62 \%$ would be rejected. If the complication rate was $\geq 53 \%$, the hypothesis that the complication rate is $\leq 42 \%$ would be rejected. The target alpha level [probability for a wrong positive decision to continue with an unsafe $\left(c \geq c_{0}\right)$ regimen] was set at $10 \%$. The target beta level [probability for a wrong negative decision to stop a safe $\left(c \leq \mathrm{c}_{1}\right)$ regimen] was set at $10 \%$, corresponding to a power of $90 \%$. Based on these assumptions, 43 evaluable patients were required.

\section{Results}

Patients and treatment

Of 70 patients screened, 64 (all-patients-treated set) received at least the first cycle (47 patients received all three planned cycles) of neoadjuvant chemotherapy, mainly $\operatorname{ECX}(n=36)$ and $\operatorname{EOX}(n=8)$. Of these patients, 58 underwent surgery and 54 (safety analysis set) received at least the first dose of catumaxomab and were therefore evaluable for the primary safety endpoint. Gastric adenocarcinoma was histologically confirmed for all 54 patients $(100 \%)$. CT was applied in $94 \%$, gastroscopy in $69 \%$ and endosonography in $59 \%$ of patients, respectively. The T-status of the primary tumour could not be assessed in three patients $(6 \%)$, at screening or during the post-chemotherapy visit, but the tumour stage was assessed during surgery. All other patients fulfilled the required T2/3/4, $\mathrm{N} \pm$ 
Table 1 Patients' baseline characteristics (safety analysis set; $n=54)$

\begin{tabular}{ll}
\hline Characteristic & Number of patients $(\%)$ \\
\hline Male/female, $n(\%)$ & $37(69) / 17(31)$ \\
Median age (range), years & $59(37-73)$ \\
Median weight (range), kg & $76(55-115)$ \\
Karnofsky Index, $n(\%)$ & \\
80 & $3(6)$ \\
90 & $27(50)$ \\
100 & $24(44)$ \\
Initial TNM stage, $n(\%)$ & \\
TXN0M0 & $1(2)$ \\
T2N0M0 & $2(4)$ \\
T2N1M0 & $4(7)$ \\
T2NXM0 & $1(2)$ \\
T3N0M0 & $9(17)$ \\
T3N1M0 & $14(26)$ \\
T3N2M0 & $2(4)$ \\
T3NXM0 & $18(33)$ \\
T4NXM0 & $1(2)$ \\
TXN1M0 & $2(4)$ \\
\hline
\end{tabular}

and M0 tumour status at screening. Patients' baseline characteristics are shown in Table 1.

After neoadjuvant chemotherapy, 3 patients $(6 \%)$ had a complete response, $13(24 \%)$ had a partial response, 19 (35\%) had stable disease, $1(2 \%)$ had progressive disease, and $18(33 \%)$ had no response recorded according to RECIST. Using the Becker criteria, a complete or subtotal regression $(<10 \%$ residual tumour) was reported for 11 patients $(20 \%)$, a partial regression was reported for 16 $(30 \%), 21(39 \%)$ had minimal or no tumour regression ( $>50 \%$ residual tumour), and no pathological response was documented for 6 patients (11\%) [24]. Resection of the primary gastric adenocarcinoma was possible in all 54 patients who were treated intraoperatively with catumaxomab. The planned D2 dissection was performed in 47 patients $(87 \%)$ and dissection of lymph nodes was performed in all 54 patients. The mean number of dissected lymph nodes was 26. After surgery, 53 of 54 patients (98\%) had no residual tumour and were classified as R0; one patient had microscopic residual tumour classified as R1. According to the pathological TNM staging after neoadjuvant chemotherapy, $28 \%$ of patients were stage I, $28 \%$ stage II, $22 \%$ stage III and $15 \%$ stage IV. The remaining $7 \%$ of patients had no evidence of disease. Resurgery was necessary in ten patients (19\%). Four patients underwent a second re-surgery and two patients had a third re-surgery. The main reason for the overall 16 re-surgeries were anastomotic leakage $(n=8)$, abscess $(n=2)$, peritonitis $(n=2)$ and wound closure problems $(n=2)$.
Table 2 Postoperative complications (safety analysis set; $n=54$ )

\begin{tabular}{lll}
\hline Postoperative complication & $\begin{array}{l}\text { Number of } \\
\text { patients }(\%)\end{array}$ & $\begin{array}{l}95 \% \\
\text { CI }\end{array}$ \\
\hline $\begin{array}{l}\text { Any postoperative complication } \\
\text { Pulmonary infection verified by chest } \\
\quad \text { X-ray or CT scan }\end{array}$ & $9(17)$ & $21-48$ \\
$8-29$ & \\
$\begin{array}{l}\text { Anastomosis insufficiency requiring } \\
\text { surgery }\end{array}$ & $6(11)$ & $4-23$ \\
$\begin{array}{l}\text { Any abscess requiring an intervention } \\
\text { Symptomatic pancreatitis }\end{array}$ & $4(7)$ & $2-18$ \\
$\begin{array}{l}\text { Thromboembolism } \\
\text { Abdominal haemorrhage requiring any } \\
\text { therapy }\end{array}$ & $2(4)$ & $1-13$ \\
$\begin{array}{l}\text { Death within 30 days after surgery } \\
\text { Symptomatic cholecystitis verified by }\end{array}$ & $0(4)$ & $1-13$ \\
$\quad$ ultrasound or CT scan & $0(0)$ & $0-10$ \\
$\begin{array}{l}\text { Ileus with grade IV clinical symptoms or } \\
\text { requiring surgery }\end{array}$ & $0(0)$ & $0-7$ \\
\hline
\end{tabular}

$C I$ confidence interval, $C T$ computed tomography

Thirty patients $(56 \%)$ received all five doses of catumaxomab (per-protocol set). Twenty-four patients (44\%) discontinued catumaxomab treatment prematurely but continued in the study. Most of these patients $(n=11$; $20 \%$ ) discontinued after the intraoperative dose of catumaxomab or after the first postoperative dose $(n=8$; $15 \%)$. The main reasons for premature discontinuation were the occurrence of adverse events $(n=17)$ and withdrawal of consent $(n=3)$.

\section{Postoperative complications}

Predefined postoperative complications were reported in 18 of 54 evaluable patients, resulting in a postoperative complication rate of $33 \%$ (95\% confidence interval $21-48 \%$ ) (Table 2). The primary endpoint (maximum complication rate $<62 \%$ ) was therefore met. The most frequent complications were pulmonary infection $(n=9$; $17 \%)$ and anastomosis insufficiency requiring surgery $(n=6 ; 11 \%)$. No death was observed within 30 days after surgery.

\section{Safety}

Adverse events $(n=623)$ that occurred after the first dose of catumaxomab were reported in all 54 patients. Thirtyeight patients $(70 \%)$ experienced grade $\geq 3$ adverse events: the most common were abdominal pain, systemic inflammatory response syndrome (SIRS) and anastomotic complications (each observed in five patients; $9 \%$ ). Serious adverse events were observed in 22 patients $(41 \%)$. No patient died before the EoT visit. Overall 269 adverse 
Table 3 Catumaxomab-related adverse events: any grade occurring in $\geq 5 \%$ of patients and all grade $\geq 3$ (safety analysis set, $n=54$ )

\begin{tabular}{|c|c|c|}
\hline \multirow[b]{2}{*}{ Adverse event } & \multicolumn{2}{|c|}{$\begin{array}{l}\text { Number of patients } \\
(\%)\end{array}$} \\
\hline & All grades & Grade $\geq 3$ \\
\hline \multicolumn{3}{|l|}{ Cytokine-release related } \\
\hline Pyrexia & $36(67)$ & $2(4)$ \\
\hline Leucocytosis & $10(19)$ & - \\
\hline Chills & $9(17)$ & - \\
\hline Hypotension & $8(15)$ & $4(7)$ \\
\hline Systemic inflammatory response syndrome & $7(13)$ & $3(6)$ \\
\hline Nausea & $7(13)$ & - \\
\hline Vomiting & $5(9)$ & - \\
\hline Body temperature increased & $5(9)$ & - \\
\hline Tachycardia & $4(7)$ & - \\
\hline \multicolumn{3}{|l|}{ Laboratory } \\
\hline Gamma-glutamyltransferase increased & $4(7)$ & $4(7)$ \\
\hline Anaemia & $4(7)$ & - \\
\hline Bilirubin increased & - & $1(2)$ \\
\hline \multicolumn{3}{|l|}{ Other } \\
\hline Abdominal pain & $9(17)$ & $3(6)$ \\
\hline Pain & $7(13)$ & - \\
\hline Diarrhoea & $6(11)$ & $2(4)$ \\
\hline Hypertension & $4(7)$ & $3(6)$ \\
\hline Fatigue & $4(7)$ & - \\
\hline Respiratory failure & $3(6)$ & $2(4)$ \\
\hline Upper abdominal pain & $3(6)$ & - \\
\hline Pleural effusion & $3(6)$ & - \\
\hline Rash & $3(6)$ & - \\
\hline Pneumonia & - & $2(4)$ \\
\hline Anastomotic complication & - & $2(4)$ \\
\hline Respiratory distress & - & $2(4)$ \\
\hline Abdominal abscess & - & $1(2)$ \\
\hline Acute respiratory distress syndrome & - & $1(2)$ \\
\hline
\end{tabular}

events were regarded as related to catumaxomab treatment. The most common catumaxomab-related adverse events were pyrexia $(n=36 ; 67 \%)$, leucocytosis $(n=10$; $19 \%)$, abdominal pain $(n=9 ; 17 \%)$ and chills $(n=9$; $17 \%$ ) (Table 3). Twenty-eight patients (52\%) experienced grade $\geq 3$ catumaxomab-related adverse events: the most common were hypotension $(n=4 ; 7 \%)$, increased gamma-glutamyltransferase $(n=4)$, abdominal pain $(n=3 ; 6 \%)$, SIRS $(n=3)$ and hypertension $(n=3)$ (Table 3). Serious adverse events related to catumaxomab treatment were observed in 13 patients (24\%). Most adverse events had completely resolved at the EoT. When assessed by infusion period (Table 4), the highest incidence of adverse events occurred after the intraoperative dose, with $96 \%$ of patients experiencing any adverse event and $76 \%$ experiencing a catumaxomab-related adverse event. Postoperative doses were better tolerated: the incidence of adverse events and catumaxomab-related adverse events decreased with each subsequent infusion to $30 \%$ and $23 \%$ of patients, respectively, after the fourth postoperative infusion (Table 4).

Efficacy

At the 4-year follow-up visit, 24 patients were alive, 24 had died, and information was unavailable for 6 [1 of whom was lost to follow-up, 5 withdrew informed consent after the first (2) and second (1 patient) dose of the study drug, and the remaining two patients, who discontinued the study drug after first dose because of adverse events, received off-protocol postoperative chemotherapy and withdrew consent for further follow-up thereafter]. None of the deaths were reported as an adverse event and tumour progression was observed before death in 22 patients. Twenty patients had no disease progression and 28 had relapsed [13 with lymph node involvement, 14 with haematological metastasis (including lung, liver and bone), 10 with local relapse, 14 with peritoneal carcinomatosis and 12 with other types of relapse]. The DFS and OS rates are shown in Table 5. The 4-year DFS and OS rates were $38 \%$ and $50 \%$. DFS and OS from surgery are shown in Fig. 1a, $\mathrm{b}$, respectively.

\section{Discussion}

In this phase II study with 4-year follow-up of catumaxomab as part of a multimodal therapy approach in primarily resectable gastric cancer, the primary endpoint was the rate of postoperative complications observed within 30 days after surgery. Postoperative complications occurred in 18 of $54(33 \%)$ evaluable patients. Thus, the $33 \%$ rate was less than the predefined maximum acceptable complication rate of $62 \%$ and is in the range of postoperative complication rates reported after surgery and neoadjuvant chemotherapy in patients with gastric or gastro-oesophageal adenocarcinoma (26-46\%) [8, 9, 25].

The most frequent postoperative complications were pulmonary infection (17\%) and anastomosis insufficiency requiring surgery $(11 \%)$. In addition, respiratory and pleural complications were reported (Table 3). Infectious and noninfectious complications of the respiratory tract, such as pneumonia, pleural empyema, pleuritis and pleural effusion, are common postoperative adverse events after gastrectomy [26-28]. The incidence of anastomosis insufficiency largely varies ranging from $2.3-4.3 \%$ in randomised phase III trials with or without preoperative chemotherapy to $9 \%$ in observational registries and even 
Table 4 Adverse events by infusion period (safety analysis set)

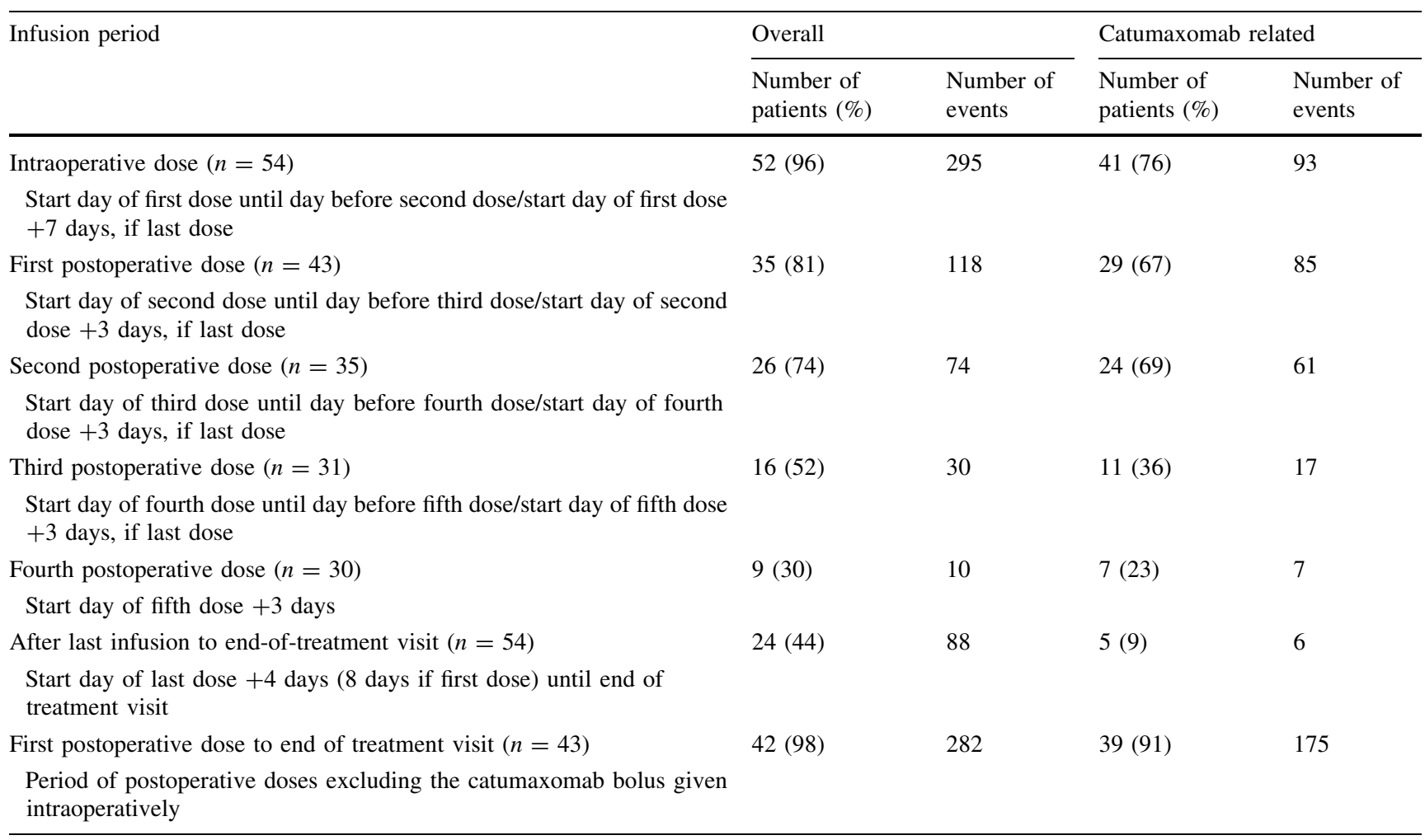

Table 5 Disease-free survival and overall survival rates from screening (safety analysis set, $n=54$ )

\begin{tabular}{clll}
\hline & $\begin{array}{l}\text { Survival rate } \\
(\%)\end{array}$ & $\begin{array}{l}95 \% \\
\text { CI }\end{array}$ & $\begin{array}{l}\text { Number of patients failed/ } \\
\text { left }\end{array}$ \\
\hline DFS & & & \\
1 year & 71 & $56-82$ & $14 / 34$ \\
2 years & 48 & $33-61$ & $25 / 23$ \\
3 years & 42 & $28-55$ & $28 / 20$ \\
4 years & 38 & $24-51$ & $30 / 18$ \\
OS & & & \\
1 year & 94 & $82-98$ & $3 / 45$ \\
2 years & 71 & $56-82$ & $14 / 34$ \\
3 years & 54 & $39-67$ & $22 / 26$ \\
4 years & 50 & $35-63$ & $24 / 24$ \\
\hline
\end{tabular}

$C I$ confidence interval, $D F S$ disease-free survival, $O S$ overall survival

$15.7 \%$ in single arm phase II trials with intensified neoadjuvant treatment $[7,25,28-30]$. Although limited by the relatively small number of patients in this trial, a potential influence of intra- and postoperative catumaxomab on anastomosis insufficiency cannot be excluded.

Most adverse events were reported after the intraoperative (first) dose of catumaxomab and their frequency and intensity decreased with each postoperative infusion. In addition, most grade $\geq 3$ adverse events occurred after the intraoperative and first postoperative doses and substantially declined after the third and fourth infusions (data not shown).

The standard catumaxomab dose schedule of four consecutive intraperitoneal infusions of $10,20,50$ and $150 \mu \mathrm{g}$ following the intraoperative dose showed acceptable tolerability in patients after intended curative resection of confirmed gastric cancer. The most common catumaxomab-related adverse events were pyrexia, leucocytosis, abdominal pain and chills, which were most probably caused by the release of cytokines (pyrexia, chills) or the intraperitoneal route of administration (abdominal pain). The adverse events were mostly mild to moderate, were reversible with symptomatic treatment and had a typical duration of $<2$ days. Overall, the safety results for the standard catumaxomab dose schedule reflect its known mode of action and are generally in line with the expected pattern of adverse events reported in previous clinical studies [17, 21, 22].

Postoperative relapse rates after perioperative and adjuvant chemotherapy remain high because of the spread of disseminated, micro-metastatic tumour cells in the peritoneal cavity. Furthermore, more than half of patients are unable to receive adjuvant chemotherapy, because of prolonged recovery or postoperative complications [8, 9]. 
Fig. 1 Kaplan-Meier survival analysis (safety analysis set, $n=54)$. a Disease-free survival; b overall survival (4year follow-up)
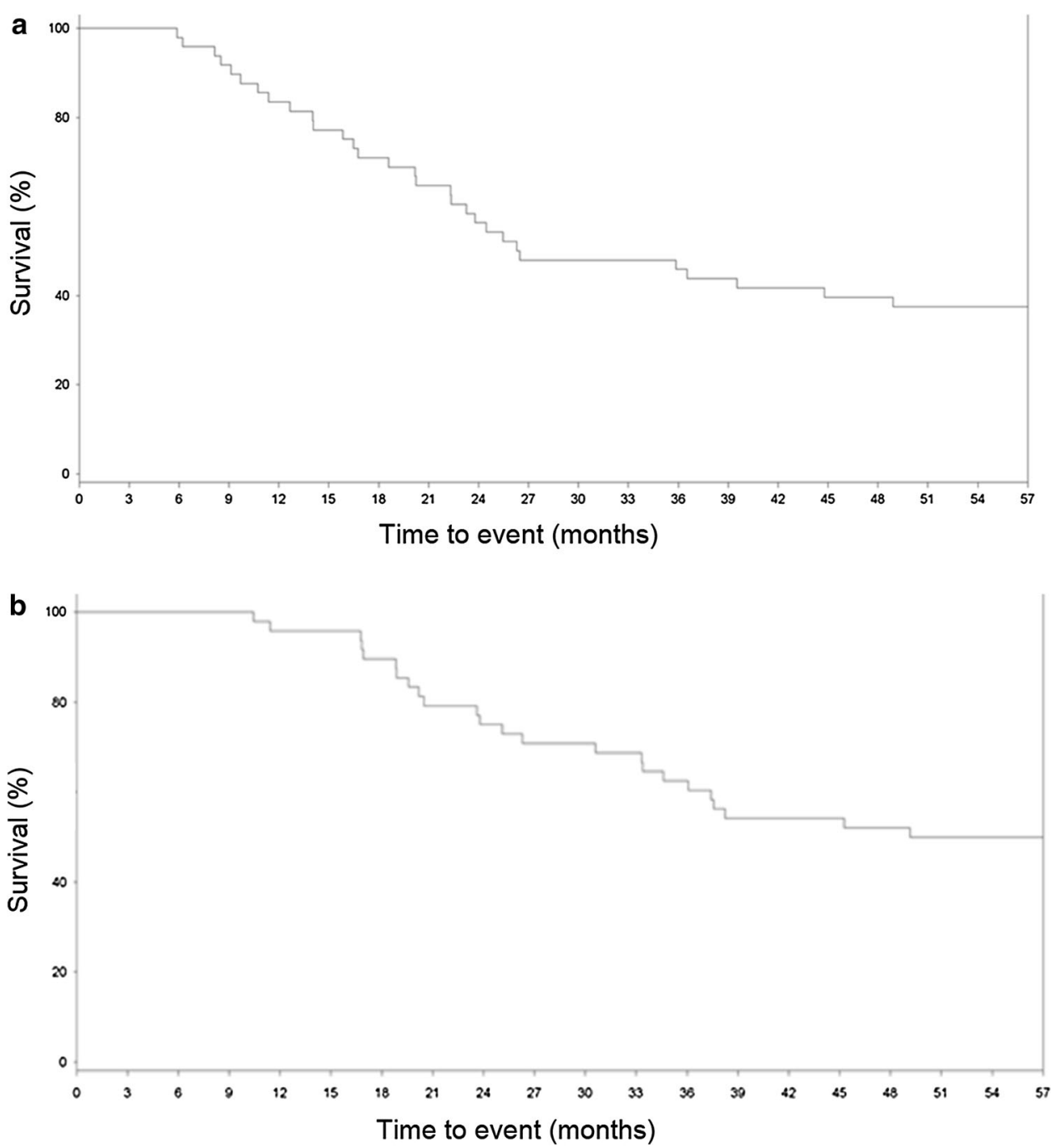

Thus, new treatment options are required. Catumaxomab as part of a multimodal therapy approach seems to be a possible option. The intra- and postoperative intraperitoneal administration of catumaxomab was designed to achieve high local concentrations at the required site of action, with the aim of eliminating residual EpCAM-positive cancer cells in the peritoneal cavity after downstaging of the tumour by neoadjuvant chemotherapy and curative resection of the primary tumour. This study demonstrates that immunotherapy with catumaxomab is feasible and might be integrated into the perioperative setting together with chemotherapy. The preoperative chemotherapeutic regimen chosen for our study was based on the ECF regimen used in the MAGIC trial and adapted according to the results of the REAL2 study [8, 31]. Intra- and postoperative catumaxomab in combination with neoadjuvant chemotherapy and surgery resulted in 4-year DFS and OS rates of $38 \%$ and $50 \%$, respectively. The efficacy results of this study are within the expected range for a perioperative treatment approach [7-9].
However, out of 54 patients starting catumaxomab after resection, 24 stopped treatment early mainly because of adverse events, indicating limited tolerability of this intraperitoneal treatment approach directly after major abdominal surgery. These numbers are similar to the rates for the standard perioperative multimodality approach with only about $40 \%$ of patients completing postoperative treatment, if chemotherapy is applied [8, 9]. Thus, the intra- and postoperative administration of catumaxomab does not seem to relevantly increase rates of completing adjuvant treatment compared to chemotherapy. The noted rate of peritoneal relapse in half of relapsing patients (14 out of 28) seems to be similar to previous reports. However, notwithstanding the limited interpretation of results based on the relatively small number of patients, the rather high rate of peritoneal recurrence despite applying a drug targeting peritoneal dissemination has to be considered. The most critical issue seems to be the distinct diagnosis of peritoneal recurrence as previously shown for a patient treated within this trial with inflammatory lesions 
mimicking peritoneal carcinomatosis on imaging and macroscopically [32]. Therefore, this case was published and trial sites were advised to confirm suspicion of peritoneal carcinomatosis on imaging by histological verification. However, the rate of confirmatory histological evaluation remained low because of the invasiveness of the procedure and reluctance of patients and treating physicians. Thus, the rate of peritoneal recurrence in this trial using an intraperitoneal immunologic treatment might be overestimated and should be interpreted with caution.

In conclusion, the primary endpoint of the study (the postoperative complication rate) was met. This, together with the safety results, shows that the intra- and postoperative administration of catumaxomab seems to be feasible and tolerable. The tolerability profile of the postoperative catumaxomab doses was consistent with that reported in previous clinical studies. The efficacy results are within the range of other perioperative treatment approaches and might thus be further investigated in a randomised trial as part of a multimodal treatment approach in patients with advanced gastric cancer.

Acknowledgments The authors would like to thank the following principle investigators who participated in the study for their continuous effort and cooperation: Germany: M. Heiss, Department of Surgery, Cologne-Merheim Medical Center, University of WittenHerdecke, Cologne; M. De Wit, Department of Oncology, Vivantes Hospital of Neukoelln, Berlin; U. Vanhoefer, Department of Medicine, Medical Oncology and Hematology, Gastroenterology, and Infectious Disease, Marienkrankenhaus, Hamburg; H.J. Schmoll, Department of Oncology/Haematology, Martin Luther University, Halle; M. Geissler, Department of Medicine, Gastroenterology and Oncology, Municipal Hospital Esslingen, Esslingen; F. Popp, Department of Surgery, University Medical Center Regensburg, Regensburg; S. Cameron, Department of Gastroenterology and Endocrinology, University Clinic of the Georg August University, Göttingen; Austria: B. Riedmann, Department of Surgery, Hospital Hall/Tirol, Hall; A. Zabernigg, Department of Internal Medicine, Kufstein County Hospital, Kufstein; G. Gastl, Department of Internal Medicine, University of Innsbruck; United Kingdom: S. Parsons, Department of Surgery, City Hospital Campus, Nottingham University NHS Trust, Nottingham; Spain: L. Cirera, Department of Oncology, Hospital Mútua de Terrassa, Terrassa. The authors would also like to thank the freelance medical writer Kevin De-Voy (funded by Neovii Biotech $\mathrm{GmbH}$ ) for his writing support. This work was supported by Neovii Biotech.

Conflict of interest Carsten Bokemeyer has acted as an advisor for Neovii Biotech $\mathrm{GmbH}$. While the research described in this manuscript was performed, Ramona Fischer was an employee at Neovii (formerly Fresenius) Biotech. The other authors have no disclosures to declare.

\section{References}

1. Ferlay J, Shin HR, Bray F, Forman D, Mathers C, Parkin DM. Estimates of worldwide burden of cancer in 2008: GLOBOCAN 2008. Int J Cancer. 2010;127:2893-917.
2. Ferlay J, Steliarova-Foucher E, Lortet-Tieulent J, Rosso S, Coebergh JW, Comber H, Forman D, Bray F. Cancer incidence and mortality patterns in Europe: estimates for 40 countries in 2012. Eur J Cancer. 2013;49:1374-403.

3. Saka M, Morita S, Fukagawa T, Katai H. Present and future status of gastric cancer surgery. Jpn J Clin Oncol. 2011;41:307-13.

4. Waddell T, Verheij M, Allum W, Cunningham D, Cervantes A, Arnold D. Gastric cancer: ESMO-ESSO-ESTRO Clinical Practice Guidelines for diagnosis, treatment and follow-up. Ann Oncol 2013;24: vi57-63.

5. Fuchs CS, Tomasek J, Yong CJ, Dumitru F, Passalacqua R, Goswami C, Safran H, Dos Santos LV, Aprile G, Ferry DR, Melichar B, Tehfe M, et al. Ramucirumab monotherapy for previously treated advanced gastric or gastro-oesophageal junction adenocarcinoma (REGARD): an international, randomised, multicentre, placebo-controlled, phase 3 trial. Lancet 2013.

6. Bang YJ, Van Cutsem E, Feyereislova A, Chung HC, Shen L, Sawaki A, Lordick F, Ohtsu A, Omuro Y, Satoh T, Aprile G, Kulikov E, et al. Trastuzumab in combination with chemotherapy versus chemotherapy alone for treatment of HER2-positive advanced gastric or gastro-oesophageal junction cancer (ToGA): a phase 3, open-label, randomised controlled trial. Lancet. 2010;376:687-97.

7. Schuhmacher C, Gretschel S, Lordick F, Reichardt P, Hohenberger W, Eisenberger CF, Haag C, Mauer ME, Hasan B, Welch J, Ott K, Hoelscher A, et al. Neoadjuvant chemotherapy compared with surgery alone for locally advanced cancer of the stomach and cardia: european Organisation for Research and Treatment of Cancer randomized trial 40954. J Clin Oncol. 2010;28:5210-8.

8. Cunningham D, Allum WH, Stenning SP, Thompson JN, Van de Velde CJ, Nicolson M, Scarffe JH, Lofts FJ, Falk SJ, Iveson TJ, Smith DB, Langley RE, et al. Perioperative chemotherapy versus surgery alone for resectable gastroesophageal cancer. N Engl J Med. 2006;355:11-20.

9. Ychou M, Boige V, Pignon JP, Conroy T, Bouche O, Lebreton G, Ducourtieux M, Bedenne L, Fabre JM, Saint-Aubert B, Geneve J, Lasser P, et al. Perioperative Chemotherapy Compared With Surgery Alone for Resectable Gastroesophageal Adenocarcinoma: an FNCLCC and FFCD Multicenter Phase III Trial. J Clin Oncol. 2011;29:1715-21.

10. Paoletti X, Oba K, Burzykowski T, Michiels S, Ohashi Y, Pignon JP, Rougier P, Sakamoto J, Sargent D, Sasako M, Van Cutsem E, Buyse M. Benefit of adjuvant chemotherapy for resectable gastric cancer: a meta-analysis. JAMA. 2010;303:1729-37.

11. Macdonald JS, Smalley SR, Benedetti J, Hundahl SA, Estes NC, Stemmermann GN, Haller DG, Ajani JA, Gunderson LL, Jessup JM, Martenson JA. Chemoradiotherapy after surgery compared with surgery alone for adenocarcinoma of the stomach or gastroesophageal junction. N Engl J Med. 2001;345:725-30.

12. Chau I, Norman AR, Cunningham D, Waters JS, Oates J, Ross PJ. Multivariate prognostic factor analysis in locally advanced and metastatic esophago-gastric cancer-pooled analysis from three multicenter, randomized, controlled trials using individual patient data. J Clin Oncol. 2004;22:2395-403.

13. Janjigian YY, Werner D, Pauligk C, Steinmetz K, Kelsen DP, Jager E, Altmannsberger HM, Robinson E, Tafe LJ, Tang LH, Shah MA, Al-Batran SE. Prognosis of metastatic gastric and gastroesophageal junction cancer by HER2 status: a European and USA International collaborative analysis. Ann Oncol. 2012;23:2656-62.

14. Yoo CH, Noh SH, Shin DW, Choi SH, Min JS. Recurrence following curative resection for gastric carcinoma. $\mathrm{Br} \mathrm{J}$ Surg. 2000;87:236-42.

15. Wu CW, Lo SS, Shen KH, Hsieh MC, Chen JH, Chiang JH, Lin $\mathrm{HJ}$, Li AF, Lui WY. Incidence and factors associated with 
recurrence patterns after intended curative surgery for gastric cancer. World J Surg. 2003;27:153-8.

16. Maehara Y, Hasuda S, Koga T, Tokunaga E, Kakeji Y, Sugimachi K. Postoperative outcome and sites of recurrence in patients following curative resection of gastric cancer. Br J Surg. 2000;87:353-7.

17. Heiss MM, Murawa P, Koralewski P, Kutarska E, Kolesnik OO, Ivanchenko VV, Dudnichenko AS, Aleknaviciene B, Razbadauskas A, Gore M, Ganea-Motan E, Ciuleanu T, et al. The trifunctional antibody catumaxomab for the treatment of malignant ascites due to epithelial cancer: results of a prospective randomized phase II/III trial. Int J Cancer. 2010;127:2209-21.

18. Seimetz D, Lindhofer H, Bokemeyer C. Development and approval of the trifunctional antibody catumaxomab (anti-EpCAMxanti-CD3) as a targeted cancer immunotherapy. Cancer Treat Rev 2010.

19. Ruf $P$, Kluge M, Jager M, Burges A, Volovat C, Heiss MM, Hess $\mathrm{J}$, Wimberger $\mathrm{P}$, Brandt B, Lindhofer $\mathrm{H}$. Pharmacokinetics, immunogenicity and bioactivity of the therapeutic antibody catumaxomab intraperitoneally administered to cancer patients. Br J Clin Pharmacol. 2010;69:617-25.

20. Schmitt M, Schmitt A, Reinhardt P, Thess B, Manfras B, Lindhofer H, Riechelmann H, Wiesneth M, Gronau S. Opsonization with a trifunctional bispecific (alphaCD3 $\mathrm{x}$ alphaEpCAM) antibody results in efficient lysis in vitro and in vivo of EpCAM positive tumor cells by cytotoxic $\mathrm{T}$ lymphocytes. Int $\mathrm{J}$ Oncol. 2004;25:841-8.

21. Baumann K, Pfisterer J, Wimberger P, Burchardi N, Kurzeder C, du Bois A, Loibl S, Sehouli J, Huober J, Schmalfeldt B, Vergote I, Luck HJ, et al. Intraperitoneal treatment with the trifunctional bispecific antibody Catumaxomab in patients with platinumresistant epithelial ovarian cancer: a phase IIa study of the AGO Study Group. Gynecol Oncol. 2011;123:27-32.

22. Strohlein MA, Lordick F, Ruttinger D, Grutzner KU, Schemanski OC, Jager M, Lindhofer H, Hennig M, Jauch KW, Peschel C, Heiss MM. Immunotherapy of peritoneal carcinomatosis with the antibody catumaxomab in colon, gastric, or pancreatic cancer: an openlabel, multicenter, phase I/II trial. Onkologie. 2011;34:101-8.

23. Gottschalk A. New criteria for ventilation-perfusion lung scan interpretation: a basis for optimal interaction with helical CT angiography. Radiographics. 2000;20:1206-10.

24. Becker K, Mueller JD, Schulmacher C, Ott K, Fink U, Busch R, Bottcher K, Siewert JR, Hofler H. Histomorphology and grading of regression in gastric carcinoma treated with neoadjuvant chemotherapy. Cancer. 2003;98:1521-30.

25. Thuss-Patience PC, Hofheinz RD, Arnold D, Florschutz A, Daum S, Kretzschmar A, Mantovani-Loffler L, Bichev D, Breithaupt K, Kneba M, Schumacher G, Glanemann M, et al. Perioperative chemotherapy with docetaxel, cisplatin and capecitabine (DCX) in gastro-oesophageal adenocarcinoma: a phase II study of the Arbeitsgemeinschaft Internistische Onkologie (AIO). Ann Oncol. 2012;23:2827-34.

26. Lee JH, Han HS. A prospective randomized study comparing open vs laparoscopy-assisted distal gastrectomy in early gastric cancer: early results. Surg Endosc. 2005;19:168-73.

27. Mohri Y, Tonouchi H, Miki C, Kobayashi M, Kusunoki M. Incidence and risk factors for hospital-acquired pneumonia after surgery for gastric cancer: results of prospective surveillance. World J Surg. 2008;32:1045-50.

28. Sano T, Sasako M, Yamamoto S, Nashimoto A, Kurita A, Hiratsuka M, Tsujinaka T, Kinoshita T, Arai K, Yamamura Y, Okajima K. Gastric cancer surgery: morbidity and mortality results from a prospective randomized controlled trial comparing D2 and extended para-aortic lymphadenectomy-Japan Clinical Oncology Group study 9501. J Clin Oncol. 2004;22:2767-73.

29. Spizzo G, Ofner D, de Vries A, Lukas P, Steger G, Pluschnig U, Zacherl J, Widder J, Zabernigg A, Gastl G, Muhlmann G. Preoperative chemotherapy with cisplatin and docetaxel followed by surgery and clip-oriented postoperative chemoradiation in patients with localized gastric or gastroesophageal junction adenocarcinoma: results from a phase II feasibility study. Ann Surg Oncol. 2011;18:677-83.

30. Sauvanet A, Mariette C, Thomas P, Lozac'h P, Segol P, Tiret E, Delpero JR, Collet D, Leborgne J, Pradere B, Bourgeon A, Triboulet JP. Mortality and morbidity after resection for adenocarcinoma of the gastroesophageal junction: predictive factors. J Am Coll Surg. 2005;201:253-62.

31. Cunningham D, Starling N, Rao S, Iveson T, Nicolson M, Coxon F, Middleton G, Daniel F, Oates J, Norman AR. Capecitabine and oxaliplatin for advanced esophagogastric cancer. N Engl J Med. 2008;358:36-46.

32. Russel J, Stein A, Behrmann C, Hauptmann S, Krummenerl P, Schmoll HJ, Arnold D. Inflammatory lesions of the peritoneum mimic carcinomatosis after treatment with intravenous chemotherapy and intraperitoneal catumaxomab. J Clin Oncol. 2011;29:e644-6. 